\title{
Assessment of social psychological determinants of satisfaction with childbirth in a cross-national perspective Wendy Christiaens* and Piet Bracke
}

\author{
Address: Department of Sociology, Ghent University, Ghent, Belgium \\ Email: Wendy Christiaens* - Wendy.Christiaens@ugent.be; Piet Bracke - Piet.Bracke@ugent.be \\ * Corresponding author
}

Published: 26 October 2007

BMC Pregnancy and Childbirth 2007, 7:26 doi:10.1 186/147I-2393-7-26
Received: 5 February 2007

Accepted: 26 October 2007

This article is available from: http://www.biomedcentral.com/I47/-2393/7/26

(c) 2007 Christiaens and Bracke; licensee BioMed Central Ltd.

This is an Open Access article distributed under the terms of the Creative Commons Attribution License (http://creativecommons.org/licenses/by/2.0), which permits unrestricted use, distribution, and reproduction in any medium, provided the original work is properly cited.

\begin{abstract}
Background: The fulfilment of expectations, labour pain, personal control and self-efficacy determine the postpartum evaluation of birth. However, researchers have seldom considered the multiple determinants in one analysis. To explore to what extent the results can be generalised between countries, we analyse data of Belgian and Dutch women. Although Belgium and the Netherlands share the same language, geography and political system and have a common history, their health care systems diverge. The Belgian maternity care system corresponds to the ideal type of the medical model, whereas the Dutch system approaches the midwifery model. In this paper we examine multiple determinants, the fulfilment of expectations, labour pain, personal control and self-efficacy, for their association with satisfaction with childbirth in a cross-national perspective.
\end{abstract}

Methods: Two questionnaires were filled out by 605 women, one at 30 weeks of pregnancy and one within the first 2 weeks after childbirth either at home or in a hospital. Of these, 560 questionnaires were usable for analysis. Women were invited to participate in the study by independent midwives and obstetricians during antenatal visits in 2004-2005. Satisfaction with childbirth was measured by the Mackey Satisfaction with Childbirth Rating Scale, which takes into account the multidimensional nature of the concept. Labour pain was rated retrospectively using Visual Analogue Scales. Personal control was assessed with the Wijma Delivery Expectancyl Experience Questionnaire and Pearlin and Schooler's mastery scale. A hierarchical linear analysis was performed.

Results: Satisfaction with childbirth benefited most consistently from the fulfilment of expectations. In addition, the experience of personal control buffered the lowering impact of labour pain. Women with high self-efficacy showed more satisfaction with self-, midwife- and physician-related aspects of the birth experience.

Conclusion: Our findings focus the attention toward personal control, self-efficacy and expectations about childbirth. This study confirms the multidimensionality of childbirth satisfaction and demonstrates that different factors predict the various dimensions of satisfaction. The model applies to both Belgian and Dutch women. Cross-national comparative research should further assess the dependence of the determinants of childbirth satisfaction on the organisation of maternity care. 


\section{Background}

In previous research some determinants of childbirth satisfaction have been proposed, but only a few authors [13 ] considered the multiple determinants within a single study. Social psychological determinants most authors agree about - expectations about childbirth, labour pain, personal control and self-efficacy - are assessed in relation to satisfaction with childbirth in one analysis. In addition, most of the research focuses on single countries. The question of course is, to what extent the results can be generalised between countries, despite huge variation in childbirth delivery practices.

Although Belgium and the Netherlands share a common history, geography and language, health care in general and maternity care in particular are differently organised. The birth systems can be placed in an international context wherein Belgium represents the mainstream obstetric practice characterised by a highly medicalised approach. The Dutch childbirth system, however, is well known for the high rate of home births. Approximately 30\% of Dutch pregnant women have a home birth [4] versus less than $2 \%$ of Belgian women [5]. In both countries women can attend primary or secondary caregivers. In the primary care system women deliver at home with a midwife, sometimes accompanied by a general practitioner. In secondary care, childbirth takes place in a hospital under supervision of an obstetrician. In the Netherlands, however, primary caregivers function as gatekeepers [6]. They refer women to secondary care in cases of a reduced chance of a normal birth. In Belgium the great majority (more than 98\%) of women consult an obstetrician immediately.

The analytical typology of van Teijlingen [7], enables us to characterise diverging maternity care systems. The medical model is the dominant paradigm in modern health care and emphasises the body-mind dualism [8] and the risky nature of childbirth. This biomedical focus is doctor-centred and pregnant women are regarded as passive patients, lacking the knowledge or authority to decide on medical treatment. The social model embraces the holistic approach and views birth as a normal physiological process. The medical status of women having children is not the only relevant information, their social roles and status are also taken into account [7]. Manifestations of the social model in the Netherlands are the strong independent midwifery profession [9], the belief in the normality of childbirth [9], the positive attitude towards home births [10], and the low obstetric intervention rates $[11,12]$ compared to other European countries. However, this does not mean that the medical model is completely absent from Dutch maternity care. De Vries [11] points to two sciences of obstetrics in the Netherlands, one in favour of and one against home births. In Belgium the medicalisation of childbirth and the absence of a strong independent midwifery profession [13] translates to the discouragement of home birth practices [5] and high intervention rates. Belgian maternity care, however, does not result in lowered average satisfaction scores in comparison to the Dutch [14].

We assessed four social psychological features - expectations about childbirth, the labour pain, personal control and self-efficacy - associated with childbirth satisfaction in one explanatory model, taking the subdimensions of satisfaction with childbirth into account. Through the use of a Belgian and Dutch sample the applicability of the model in divergent maternity care systems is explored.

\section{Literature review}

Despite a considerable amount of research, satisfaction is poorly defined [15]. Theoretical models regarding patient satisfaction, such as the discrepancy and fulfilment theory [15] and the value-expectancy model [16], are relied on. Following Linder-Pelz [16], we define satisfaction as positive evaluations of distinct dimensions of childbirth. It is generally agreed that satisfaction is a multidimensional concept, influenced by a variety of factors [17]. This means that women can be satisfied with some aspects of childbirth and dissatisfied with others [18]. A review of the literature indicates four main determinants of childbirth satisfaction: labour pain [19-23], personal control $[15,20,21,23,24]$, self-efficacy $[25,26]$ and expectations for labour and birth [19-21].

\section{Labour pain}

Reports about the relationship between the intensity of pain and satisfaction seem to provide mixed results. Some researchers found that painful experiences result in lowered satisfaction $[1,19,27-29]$, others pointed out that the experience of high levels of pain does not necessarily bring about a dissatisfied mother [2,30]. In a longitudinal study assessing the quality of women's birth experience, Doering et al. [1] reported that pain does reduce the quality of the birth experience, but even so, remaining in control is more important to a pleasurable experience. In a systematic review Hodnett [18] concluded that pain and pain relief do not play a major role in childbirth satisfaction, unless expectations regarding either are unmet. Apparently, if the question about the influence of the experience of labour pain on satisfaction with childbirth is rigorously reviewed a considerable consensus is reached. Associations between pain intensity and other determinants of satisfaction, e.g., control and the fulfilment of expectations, are suggested.

\section{Expectations about childbirth}

Many authors pointed to the evaluative aspect of childbirth satisfaction $[15,16,18,31]$. Janzen et al. [32] defined 
satisfaction, corresponding with the "discrepancy" model $[17,33]$, as "the experience which results from the subjective evaluation of the distinction between what actually occurred and what the individual thinks should have" (2006, p. 44).

Expectation as a determinant of satisfaction is related to the need for the familiar, which means that socially created expectations influence satisfaction [34]. Expectations refer to a role system. The role of a labouring woman involves a set of expectations concerning her own behaviour and of people in other roles such as the midwife, the partner, or the physician. By demanding the expected of one's self and each person present, a workable order is created. Violation of expectations disturbs this order and threatens both self-evaluations and relationships with others. In other words, the deviation from what is normal or expected creates distress [35]. Satisfaction is a state of mind reflecting the evaluation of the birth experience as a whole compared with several antenatal values and expectations. If expectations are met, the corresponding values and beliefs are affirmed. If not, conflicts arise, which may bring about distress. However, as Pearlin [36] stated, mediating factors can play a buffering role between the discrepancy and the reaction to it. Personal control is one of those mediators.

Many conceptualisations of satisfaction refer to expectations as a major determining factor of satisfaction $[34,37$ 39]. Researchers have shown that women whose expectations for childbirth are met are more satisfied than those whose expectations are not $[2,19,20]$. Expectations related to several aspects of labour and delivery, such as emotions $[20,40]$, the length of labour [41], the need for interventions $[20,40]$, the condition of the child [41], and the support of the partner and the medical staff [40], have been researched. Although the fulfilment of expectations received some attention in the childbirth satisfaction literature, it has not yet been included in a model with multiple determinants, except by Goodman et al.[2].

\section{Personal control and self-efficacy}

Personal control has been shown to be the strongest predictor of satisfaction with childbirth [2]. Many authors point to the perception of control during birth as essential to feeling satisfied and empowered $[1,15,19,20,30,41,42]$, even if expectations are violated. Although pain management is the best short-term solution to help women cope with childbirth, personal control provides a long-term benefit [30]. If women participate actively, they are empowered by the experience of control [43]. Moreover this empowering experience has a cumulative effect, increasing self-efficacy for the next birth [20]. We distinguished between perceived personal control and self-efficacy. The latter reflects a personality characteristic of confidence in the ability to cope with any stressful situation [44], which predicts a positive childbirth experience [45]. Self-efficacy is also related to lower levels of pain $[26,46]$ and method of delivery [47]. Personal control refers to the opposite of powerlessness, which is a type of alienation [48]. Alienation is thought to be a consequence of the medicalisation of childbirth [49]. The degree of women-centeredness and medicalisation of care varies according to place of birth [50] and the maternity care system [7].

Determinants such as childbirth expectations [51] and personal control [52] have been shown to be strongly related to the birth environment. The results of these studies suggest that the influence of childbirth expectations and personal control can be context specific, hence different for Dutch and Belgian women.

The purpose of our study is to assess the influence of expectations about childbirth, labour pain, personal control and self-efficacy on Belgian and Dutch women's satisfaction with childbirth.

\section{Methods}

\section{Selection of method}

This study modelled the relationships between satisfaction with childbirth and labour pain, expectations about childbirth, personal control and self-efficacy, using data collected from a self-reported survey. To contact as many women as possible in a short period of time, a survey by two questionnaires - one at 30 weeks of pregnancy and one within 2 weeks postpartum - was considered to be appropriate. Because of the longitudinal design the same concepts were measured before and after birth, hence the antenatal and postnatal questionnaires were similar. From the time the invitation to participate was issued, to the completion of the last questionnaire, five to eight months passed. Since the data collection was not simultaneously organised in each hospital/midwifery practice, one year - from September 2004 to September 2005 - was necessary to gather the data.

\section{Settings}

Satisfaction with childbirth was studied in two different health care contexts, namely Belgium and the Netherlands. The Netherlands are well-known as an important exception to the worldwide trend of institutionalisation and medicalisation of childbirth [53]. No other region resembles the Dutch society more closely than Belgium does. Still, Belgian maternity care is strikingly different. The study concerned two comparable cities in the Belgian and Dutch regions, respectively. To enhance the readability of the paper we will refer to Belgium and the Netherlands, and the Belgians and the Dutch. Both hospital and 
home births are included, because it has been shown that place of birth influences satisfaction with childbirth [52].

\section{Sample size}

Since the population of pregnant women is unknown, we had to rely on a convenience sample. With regard to the hospital births all hospitals in both cities were approached. In Ghent there are four hospitals of which three agreed to participate. We have no reasons to believe that the population of the missing hospital differs from the population in the participating hospitals. In Tilburg both hospitals agreed to cooperate. Since there are more hospital than home births in both countries, we needed to over sample the home deliveries. In Tilburg six midwifery practices were contacted to reach enough women planning a home delivery. Ghent does not count enough midwifery practices to attain the same number of home births. Therefore, the city borders of Ghent were exceeded and 21 midwifery practices spread out over Flanders were contacted. This was necessary to compare the four kinds of birth settings determined by country (Belgium versus the Netherlands) and place of birth (home versus hospital births). Sample size calculations based on a 0.95 confidence interval suggested that 600 study participants were needed for a reliable statistical analysis. At 30 weeks of pregnancy, 827 women filled out the antenatal questionnaire; 605 of those women also participated in the study in the first 2 weeks after delivery and completed a second questionnaire.

\section{Recruitment and data collection}

During antenatal visits, women were asked by their midwife or obstetrician to participate in the research project. Inclusion criteria were wide: both Belgian and Dutch women had to speak and understand Dutch, and had to be 18 years or older. The antenatal questionnaire was handed out during an antenatal visit at 30 weeks of pregnancy together with a prepaid envelope and an information sheet. It was returned to the obstetrician or midwife during one of the following antenatal visits. Within a few days after delivery, women received the postnatal questionnaire from the medical staff in case of a hospital birth, or from the midwife in case of a home birth. Women who delivered in a hospital completed the postnatal questionnaire during their postpartum stay on the maternity ward. Women with a short stay or home birth, however, responded by direct mail instead. Ante- and postnatal questionnaires were given a code, to facilitate the merging of the ante- and postnatal information belonging to the same respondent.

Women were recruited during antenatal visits to their obstetricians and midwives. Therefore, we had little control over the inclusion process and, consequentially, the response rate. Although we asked that women who refused to participate be registered, this was not systematically done in every hospital. As a result, we do not know the exact number of women invited to participate in this study. To calculate the response rate we used the number of provided questionnaires, which is based on an estimate of eligible women made by midwives and obstetricians acting as proxy. The response rate is calculated by dividing the number of respondents by the number of provided questionnaires. This calculation resulted in an average of $43 \%(\mathrm{n}=238)$ for all Belgian hospitals, $41 \%(\mathrm{n}=137)$ for Belgian midwifery practices, $42 \%(\mathrm{n}=208)$ for Dutch hospitals, and $54 \%(\mathrm{n}=244)$ for Dutch midwifery practices. The smallest response rate for the hospitals was $19 \%$, the highest $68 \%$. For the midwifery practices the response rate was $38 \%$ and $100 \%$ respectively.

\section{Ethical considerations}

A written informed consent was asked of all respondents. Anonymity has been guaranteed, since the researchers have no information about the identity of the respondent. The Committee for Ethics of the University Hospital has approved the study. Ethical approval was gained in Ghent only. In the Netherlands, approval from a research Ethics committee is not required if no interventions take place during the research. It has been explained to potential participants that they were free to participate and that their privacy was guaranteed.

\section{Measurement}

\section{Dependent variables}

Satisfaction is measured by the Mackey Childbirth Satisfaction Rating Scale, which consists of six subdimensions - general satisfaction (three items) and satisfaction with self (nine items), baby (three items), midwife (nine items), physician (eight items), and partner (two items) thus reflecting the multidimensional nature of the concept. Each dimension corresponds to a separate dependent variable in our analysis. The scale was designed by $\mathrm{M}$. Mackey and P. Goodman [2]. The scale was translated for Belgian and Dutch women. Pilot testing demonstrated that the instrument was valid. The sample Goodman et al. [2] used was limited to low-risk postpartum women with uneventful vaginal deliveries, whereas our sample extends the scope to women with instrument deliveries. Respondents indicate their degree of satisfaction with each item on a 5-point Likert scale. Internal consistency reliability coefficients (Cronbach's alpha for $\mathrm{N}=605$ ) for this study (total scale: $\alpha=0.95$; self: $\alpha=0.84$; baby: $\alpha=0.74$; midwife: $\alpha=0.96$; physician: $\alpha=0.94$; partner: $\alpha=0.85$; general: $\alpha=0.71$ ) are similar to those established by Goodman et al. [2] (total scale: $\alpha=0.94$; self: $\alpha=0.90$; baby: $\alpha=0.70$; midwife: $\alpha=0.97$; physician: $\alpha=0.83$; partner: $\alpha=0.97$; and, general: $\alpha=0.93$ ). This means that the items measuring one subscale cluster together in the translated version to the same extent as in the original 
English version of the scale. For each subscale, means were calculated.

\section{Independent variables}

Two Visual Analogue Scales (VAS) - one about labour and one about delivery - measured the experience of pain, ranging from no pain at all (0) to unbearable pain (100). Mean scores were calculated to merge both scales to one indicator of pain intensity. The measurement of labour pain by visual analogue scales is common practice in research on childbirth [54-56] and has been found to be reliable for estimating pain intensity. In comparison to more complex pain measures, the VAS is preferable $[57,58]$.

To measure personal control, three items from the Wijma Delivery Expectancy/Experience Questionnaire (W-DEQ) were isolated (Cronbach's $\alpha=0.67$ ). The items are "I behaved extremely badly" to "I didn't behave badly at all"; "I dared to totally surrender control to my body" to "I did not dare surrender control to my body at all"; "I lost total control of myself" to "I did not lose control of myself at all", and they were scored from zero to six [59]. The WDEQ was developed in Dutch to measure fear related to childbirth by assessing women's expectations before and experiences after childbirth. Because the entire scale is too broad in scope and shows overlap with the pain measure, only the control-related items were isolated in order to assess the control experience during delivery. In addition we used the seven-item mastery scale developed by Pearlin and Schooler [60] to measure self-efficacy. The seven items are: "I have little control over the things that happen to me", "There is really no way I can solve some of the problems I have", "There is little I can do to change many of the important problems I have", "I often feel helpless in dealing with the problems of life", "Sometimes I feel that I'm being pushed around in life", "What happens to me in the future mostly depends on me", and "I can do just about anything I really set my mind to do"; each item has five answer options ranging from 'strongly agree' to 'strongly disagree'. The psychometric properties of the Dutch version of this scale have been successfully tested in a study by Kempen [61]. The reliability of this scale as measured by Cronbach's alpha was 0.79 .

The degree to which expectations concerning childbirth are fulfilled was measured by the question, "To what degree was your experience of childbirth as expected?" The four answer options ranged from "not at all" to "completely in accordance with my expectations".

We controlled for childbirth characteristics such as length of labour, the planned place of birth and the method of delivery. The length of labour was a self-reported indicator. Respondents filled in when labour started and when the baby was born. The method of delivery gave an indication of how the child was born: spontaneously $(=0)$ or with a medical intervention such as a $\mathrm{C}$-section, a vacuum extraction or a forceps delivery $(=1)$. We asked for the intended place of birth in the antenatal questionnaire using the following question: Where would you like to give birth? Answer categories were: in hospital, policlinical, at home, in a birth clinic, other, I don't know. Hence this variable consisted of two broad categories, the home $(=0)$ versus the hospital $(=1)$, as intended place of birth. Women planning for a birth in a birth clinic were considered primary care clients, because a birth clinic is a substitution for the home and is not considered a medically sophisticated environment. Planning for a policlinical birth or short stay was coded as a hospital birth, notwithstanding that in some cases only midwives provided care. Nobody had a place in mind other than the ones summed up. Women who had not yet made up their minds about the place of birth $(\mathrm{N}=6)$ were coded as missing value. Following De Vries and Lemmens [62] we based the analysis on planned rather than actual place of birth, because the most complicated births end up in a hospital. This strategy avoids a positive bias towards home births and a negative bias towards hospital births.

Also socio-demographic characteristics were included as control variables: level of education $(0=$ no higher education; $1=$ higher education $)$, marital status $(0=$ married $/$ cohabiting; $1=$ single $)$, parity $(0=$ primiparous; $1=$ multiparous), age in years, and employment status $(0=$ unemployed; 1 = employed).

\section{Data analysis}

To explore the data, descriptive statistics and correlations among the study variables were reported. Because the dataset is hierarchically structured, and in order to control for clustering of women within countries, a hierarchical linear model with women (first level) nested within countries (second level) was fitted to the data. Multilevel models take into account dependence among cases from the same context to produce parameter estimates and standard errors that are more accurate. Estimations were performed using the mixed model procedure of SPSS 12.0 for total childbirth satisfaction and each subdimension, using restricted maximum likelihood estimation [63]. Two models were estimated. The first model contains the main effects of the social psychological determinants - labour pain, personal control, self-efficacy and the fulfilment of expectations - together with childbirth characteristics place of birth, method of delivery and length of labour to estimate the main effects. The regression equation of this model on the level of individual women is

$Y_{i j}=\beta_{0 j}+\beta_{1 j}\left(\right.$ Education $\left._{i j}\right)+\beta_{2 j}\left(\right.$ Maritalstatus $\left._{i j}\right)+\beta_{2 j}\left(\right.$ Parity $\left._{i j}\right)$ $+\beta_{3 j}\left(\right.$ Age $\left._{i j}\right)+\beta_{4 j}\left(\right.$ Employment $\left._{i j}\right)+\beta_{5 j}\left(\right.$ Length of lobour $\left._{i j}\right)+\beta_{6 j}$ 
$\left(\right.$ Placeof $\left._{\text {birth }}\right)+\beta_{7 j}\left(\right.$ Methodof delivery $\left._{i j}\right)+\beta_{8 j}\left(\right.$ Labour pain $\left._{i j}\right)$

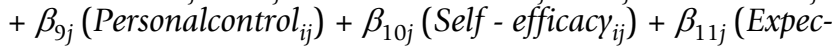
tations $\left._{i j}\right)+\beta_{12 j}\left(\right.$ Personalcontrol $_{i j}{ }^{*}$ Labour Pain $\left._{i j}\right)+r_{i j}$

where $Y_{i j}$ is one of the subdimensions of satisfaction with childbirth (total, general, self, baby, midwife, physician, partner) of women $\mathrm{i}$ in county $\mathrm{j}$ experienced shortly after birth, $\beta_{0 j}$ is the women-level intercept; $\beta_{1 j}$ to $\beta_{12 j}$ are the effects of the control variables, characteristics of childbirth and social-psychological determinants of satisfaction, and $r_{i j}$ is the error term.

At the country level the model is

$$
\beta_{0 j}=\gamma_{00}+u_{0 j}
$$

where $\gamma_{00}$ is the organization-level intercept and $u_{0 j}$ is the error term. No effects of country-level characteristics are included. Substituting the country-level equation into the individual-level equation gives the combined model in the following equation

$Y_{i j}=\gamma_{00}+\beta_{1 j}\left(\right.$ Education $\left._{i j}\right)+\beta_{2 j}\left(\right.$ Maritalstatus $\left._{i j}\right)+\beta_{2 j}\left(\right.$ Parity $\left._{i j}\right)$ $+\beta_{3 j}\left(\right.$ Age $\left._{i j}\right)+\beta_{4 j}\left(\right.$ Employment $\left._{i j}\right)+\beta_{5 j}\left(\right.$ Length of lobour $\left._{i j}\right)+\beta_{6 j}$

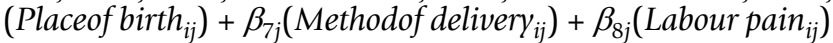
$+\beta_{9 j}\left(\right.$ Personalcontrol $\left._{i j}\right)+\beta_{10 j}($ Self - efficacy $i j)+\beta_{11 j}\left(\right.$ Expec- $^{-}$ tations $\left._{i j}\right)+\beta_{12 j}$ (Personalcontrol $_{i j}{ }^{*}$ Labour Pain $\left._{i j}\right)+u_{0 j}+r_{i j}$

To test whether the determinants apply equally to both Belgian and Dutch women, a second model containing between-county interaction terms of the social psychological determinants and the childbirth characteristics was included. In both models, level of education, marital status, parity, age and employment status were controlled for in this analysis. No random effects were included in the model structure. Because we fitted a parsimonious model, non-significant interactions with country were not included in the final model.

\section{Results}

Within the first 2 weeks after delivery, 605 women, of which 261 are Belgian and 344 are Dutch, filled out a questionnaire. In our analysis we focused on this followup data. The number of cases in the analysis dropped to 560 because 51 women failed to provide information on one of the determinants in the model. For the subscale of satisfaction with the doctor the number of cases dropped to 393 because women with a home birth did not see a physician and therefore did not answer the physicianrelated items.

\section{Descriptives}

The age of participating women ranged between 19 and 44 years, with a mean of 31.2 years, 30.4 for Belgian women and 31.9 for Dutch women. Those having their first baby made up $54.2 \%$ of all respondents, with $42.2 \%$ in Belgium and $51.8 \%$ in the Netherlands. Approximately $98.0 \%$ of the respondents were married or living as married in both Belgium and the Netherlands. More Belgian $(76.9 \%)$ than Dutch $(40.5 \%)$ women have completed higher education, and $85.3 \%$ of all women were employed, with $85.3 \%$ in Belgium and $84.8 \%$ in the Netherlands (Table 1 ). This means parity and educational level may confound the comparison between Belgium and the Netherlands. Therefore these variables were controlled for in the hierarchical linear model.

The mean length of labour in our sample was approximately 10 hours for both Belgian and Dutch women. Of the respondents, $22.5 \%$ had a medical intervention. The mean pain experience was $57.6(\max .=100)$. The moderate score is a result of the pain medications used by $32.8 \%$ of the respondents. The mean pain score for women who gave birth without painkillers is 62.1. A total of $64.8 \%$ reported that their expectations about childbirth were met (Table 1).

Overall women reported a high childbirth satisfaction (mean $=4.21 ; \mathrm{SD}=0.53 ;$ max. $=5)$, but the mean scores differed along the subscales (Table 2). Satisfaction with self-related aspects of childbirth was lowest $($ mean $=3.81$; $\mathrm{SD}=0.71$, while satisfaction with partner-related aspects was highest $($ mean $=4.65 ; \mathrm{SD}=0.53)$.

\section{Hierarchical linear model}

The results of seven hierarchical analyses are summarised in Table 3. We will first concentrate on the main effects, and continue further on with the country-specific effects (no table). We present the regression coefficients (B) and the significance of the findings (P-value) between brackets. Standardised regression coefficients $(\beta)$ can be found in table 3. First, total satisfaction benefited from a feeling of being in control $(\mathrm{B}=0.14, P<0.001)$ and from a high degree of self-efficacy ( $B=0.14, P<0.001)$. Also the fulfilment of expectations ( $\mathrm{B}=0.13, P<0.001)$ improved total childbirth satisfaction, whereas this was not the case for perceived pain ( $\mathrm{B}=-0.001, P=0.341)$. Second, we consider the subdimensions of satisfaction with childbirth. General satisfaction was improved by every social psychological determinant (expectations: $\mathrm{B}=0.24, P<$ 0.001 ; personal control: $\mathrm{B}=0.15 ; P<0.001$; self-efficacy: $\mathrm{B}=0.11 ; P=0.017$ ) in our model, except for labour pain $(B=-0.01, P<0.001)$, which had a small lowering effect. Issues of control and decision-making were central to the self-related satisfaction scores. Not surprisingly, selfrelated satisfaction was enhanced by feelings of control (B $=0.23, P<0.001)$ and self-efficacy $(\mathrm{B}=0.18, P<0.001)$. Also, one's own performance was more positively evaluated when expectations were met $(B=0.17, P<0.001)$. Equally, the first contact with the baby was more satisfy- 
Table I: Descriptive statistics in total and for Belgian and Dutch women separately

\begin{tabular}{|c|c|c|c|c|}
\hline & & Total & Belgium & The Netherlands \\
\hline \multicolumn{5}{|c|}{ Socio-demographic variables } \\
\hline \multirow{3}{*}{ Higher education } & $\%$ & 57.11 & 76.99 & 40.50 \\
\hline & $\mathrm{n}$ & 329 & 194 & 135 \\
\hline & $\mathrm{Cl}$ & $0.55-0.59$ & $0.75-0.79$ & $0.38-0.43$ \\
\hline \multirow[t]{3}{*}{ Married/cohabitating } & $\%$ & 98.40 & 97.90 & 98.90 \\
\hline & $\mathrm{n}$ & 596 & 257 & 339 \\
\hline & $\mathrm{Cl}$ & $0.976-0.988$ & $0.978-0.979$ & $0.988-0.989$ \\
\hline \multirow[t]{3}{*}{ Primiparae } & $\%$ & 54.20 & 48.20 & 51.80 \\
\hline & $\mathrm{n}$ & 276 & 133 & 143 \\
\hline & $\mathrm{Cl}$ & $0.51-0.55$ & $0.45-0.5 I$ & $0.48-0.54$ \\
\hline \multirow[t]{3}{*}{ Employed } & $\%$ & 85.28 & 85.23 & 84.82 \\
\hline & $\mathrm{n}$ & 517 & 221 & 296 \\
\hline & $\mathrm{Cl}$ & $0.84-0.87$ & $0.84-0.88$ & $0.83-0.87$ \\
\hline \multirow[t]{4}{*}{ Age } & Mean & 31.21 & 30.41 & 31.87 \\
\hline & SD & 4.17 & 4.09 & 4.14 \\
\hline & $\mathrm{n}$ & 816 & 372 & 444 \\
\hline & $\mathrm{Cl}$ & $31.06-31.36$ & $30.20-30.62$ & $31.68-32.07$ \\
\hline \multicolumn{5}{|c|}{ Characteristics of childbirth } \\
\hline \multirow[t]{3}{*}{ Length of labour (expressed in hours) } & Mean & 9.48 & 9.95 & 9.13 \\
\hline & SD & 6.31 & 6.13 & 6.44 \\
\hline & $\mathrm{Cl}$ & $9.22-9.74$ & $9.57-10.34$ & $8.79-9.47$ \\
\hline \multirow{3}{*}{ With medical intervention $(I)$} & $\%$ & 22.50 & 20.80 & 23.90 \\
\hline & $\mathrm{n}$ & 133 & 54 & 79 \\
\hline & $\mathrm{Cl}$ & $0.21-0.24$ & $0.18-0.23$ & $0.22-0.26$ \\
\hline \multirow[t]{3}{*}{ Planning for a home birth $(0)$} & $\%$ & 37.00 & 24.00 & 48.00 \\
\hline & $\mathrm{n}$ & 301 & 90 & 211 \\
\hline & $\mathrm{Cl}$ & $0.35-0.39$ & $0.22-0.26$ & $0.46-0.50$ \\
\hline \multicolumn{5}{|c|}{ Social psychological variables } \\
\hline \multirow[t]{3}{*}{ Labour pain } & Mean & 57.55 & 58.04 & 57.55 \\
\hline & SD & 22.02 & 22.33 & 21.67 \\
\hline & $\mathrm{Cl}$ & $56.66-58.45$ & $56.67-59.42$ & $56.38-58.72$ \\
\hline \multirow[t]{3}{*}{ Personal control } & Mean & 4.34 & 4.27 & 4.37 \\
\hline & SD & 1.24 & 1.19 & 1.29 \\
\hline & $\mathrm{Cl}$ & $4.28-4.39$ & $4.20-4.35$ & $4.30-4.44$ \\
\hline \multirow[t]{3}{*}{ Self-efficacy } & Mean & 3.89 & 3.89 & 3.89 \\
\hline & SD & 0.53 & 0.53 & 0.53 \\
\hline & $\mathrm{Cl}$ & $3.87-3.91$ & $3.86-3.92$ & $3.87-3.92$ \\
\hline \multirow[t]{3}{*}{ Expectations met } & Mean & 2.59 & 2.69 & 2.50 \\
\hline & SD & 0.96 & 0.93 & 0.97 \\
\hline & $\mathrm{Cl}$ & $2.55-2.63$ & $2.63-2.75$ & $2.44-2.55$ \\
\hline
\end{tabular}

ing if it corresponded with expectations $(\mathrm{B}=0.15, P<$ 0.001). The same $(B=0.10, P=0.001)$ applies for the midwife, who was more positively evaluated by women with high self-efficacy $(\mathrm{B}=0.10, P=0.041)$. Personal control interacted with labour pain $\left(\mathrm{B}_{\text {pain }}{ }^{*}\right.$ control $=0.002, P=$ 0.012 ), which means that women were generally satisfied about the midwife when they felt in control, even when suffering from serious labour pain, but the B-coefficient is very small. The evaluation of the physician was positively influenced by the self-efficacy ( $\mathrm{B}=0.19, P=0.008$ ) of the women, whereas pain intensity $(B=0.003, P=0.107)$ and the fulfilment of expectations $(B=0.08, P=0.069)$ were of no importance. The more pain $(B=0.002 ; P=0.036)$ and personal control $(B=0.052 ; P=0.008)$ women experienced during childbirth, the more satisfied they were with the support of their partner, but again these relations were weak. 
Table 2: Means, skewness and kurtosis for each subdimension of the Mackey Childbirth Satisfaction Rating Scale in total and for Belgian and Dutch women $(N=605)$

\begin{tabular}{|c|c|c|c|c|c|}
\hline $\begin{array}{l}\text { Satisfaction with } \\
\text { childbirth }\end{array}$ & & Total & Belgium & The Netherlands & $\begin{array}{l}\text { Potential min. - max } \\
\text { Real min. - max. }\end{array}$ \\
\hline \multirow[t]{3}{*}{ Total } & Mean (SD) & $4.21(0.53)$ & $4.37(0.46)$ & $4.08(0.54)$ & $1.00-5.00$ \\
\hline & Skewness (SE) & $-0.97(0.10)$ & $-1.34(0.15)$ & $-0.77(0.13)$ & $2.15-5.00$ \\
\hline & Kurtosis (SE) & $1.04(0.20)$ & $3.25(0.30)$ & $0.37(0.26)$ & \\
\hline \multirow[t]{3}{*}{ General } & Mean (SD) & $4.03(0.72)$ & $4.14(0.68)$ & $3.93(0.74)$ & $1.00-5.00$ \\
\hline & Skewness (SE) & $-0.86(0.10)$ & $-1.00(0.15)$ & $-0.75(0.13)$ & $1.00-5.00$ \\
\hline & Kurtosis (SE) & $0.80(0.20)$ & $1.13(0.30)$ & $0.63(0.26)$ & \\
\hline \multirow[t]{3}{*}{ Self } & Mean (SD) & $3.8 I(0.7 I)$ & $3.99(0.66)$ & $3.67(0.72)$ & $1.00-5.00$ \\
\hline & Skewness (SE) & $-0.65(0.10)$ & $-0.81(0.15)$ & $-0.58(0.13)$ & $1.25-5.00$ \\
\hline & Kurtosis (SE) & $0.34(0.20)$ & $1.24(0.30)$ & $-0.04(0.26)$ & \\
\hline \multirow[t]{3}{*}{ Baby } & Mean (SD) & $4.39(0.77)$ & $4.48(0.77)$ & $4.34(0.76)$ & $1.00-5.00$ \\
\hline & Skewness (SE) & $-1.63(0.10)$ & $-2.00(0.15)$ & $-1.42(0.13)$ & $1.00-5.00$ \\
\hline & Kurtosis (SE) & $2.98(0.20)$ & $4.52(0.30)$ & $2.34(0.26)$ & \\
\hline \multirow[t]{3}{*}{ Midwife } & Mean (SD) & $4.46(0.66)$ & $4.62(0.55)$ & $3.32(0.73)$ & $1.00-5.00$ \\
\hline & Skewness (SE) & $-1.89(0.10)$ & $-2.91(0.15)$ & $-1.44(0.13)$ & $1.00-5.00$ \\
\hline & Kurtosis (SE) & $4.68(0.20)$ & $13.04(0.30)$ & $2.40(0.26)$ & \\
\hline \multirow[t]{3}{*}{ Physician } & Mean (SD) & $4.20(0.75)$ & $4.36(0.72)$ & $4.07(0.75)$ & $1.00-5.00$ \\
\hline & Skewness (SE) & $-1.29(0.12)$ & $-1.98(0.76)$ & $-0.88(0.14)$ & $1.00-5.00$ \\
\hline & Kurtosis (SE) & $2.14(0.24)$ & $5.38(0.35)$ & $0.85(0.33)$ & \\
\hline \multirow[t]{3}{*}{ Partner } & Mean (SD) & $4.65(0.53)$ & $4.74(0.46)$ & $4.59(0.57)$ & $1.00-5.00$ \\
\hline & Skewness (SE) & $-1.52(0.10)$ & $-1.53(0.15)$ & $-1.419(0.134)$ & $1.50-5.00$ \\
\hline & Kurtosis (SE) & $2.44(0.20)$ & $1.19(0.30)$ & $2.424(0.268)$ & \\
\hline
\end{tabular}

In addition we want to mention that women having birth in hospital reported lower satisfaction in total $(B=-0.17$, $P<0.001$ ), and for some of the subdimensions (self: $\mathrm{B}=$ $-0.26, P<0.001$; midwife: $\mathrm{B}=-0.19, P=0.001)$. Longer labours resulted in lower general satisfaction, although the association is weak $(\mathrm{B}=-0.016, P<0.001)$. Total satisfaction and most subdimensions of satisfaction decreased in cases where medical interventions occurred (Total: $\mathrm{B}=-0.19 ; P<0.001$; general: $\mathrm{B}=-0.22 ; P=0.001$; self: $\mathrm{B}=-0.123 ; P=0.044$; baby: $\mathrm{B}=-0.66 ; P<0.001$; midwife: $\mathrm{B}=-0.18 ; P=0.011$ ). Finally, parity (no table) was associated with general satisfaction $(B=0.14, P=0.014)$ and with self $(\mathrm{B}=0.12, P=0.019)$ and baby-related $(\mathrm{B}=$ $0.16, P=0.015)$ satisfaction, indicating that multiparous mothers tended to be more satisfied.

Additional analyses (no table) learned that, in general, the abovementioned results apply equally to Belgian and Dutch women. Nevertheless, two country-specific effects occurred. First, results showed that women with home births were more satisfied, especially in Belgium (general: $\mathrm{B}_{\text {place } *^{*} \text { country }}=0.35, P<0.001$; self: $\mathrm{B}_{\text {place } *^{*} \text { country }}=0.43, P<$ $0.001)$. This 'place of birth'*'country' interaction effect totally explained the between-country differences in selfrelated satisfaction. Second, Dutch women's self-related satisfaction $\left(\mathrm{B}_{\text {control }}{ }^{*}\right.$ country $\left.=0.08, P=0.040\right)$ was lower than that of Belgian women, especially when they experienced control loss, but the coefficient was small. Despite significant p-values, these country-specific effects added little to the model, since the likelihood ratio test $\left(\mathrm{p}_{\text {general }}>\right.$ $0.25 ; \mathrm{p}_{\text {self }}>0.10$ ) was not significant.

The variance of each outcome of the Mackey Childbirth Satisfaction Rating Scale explained by covariates, ranges between 3\% of satisfaction with the partner's support and $42 \%$ for self-related aspects of the birth experience (Table $3)$.

In sum, the fulfilment of expectations is the most consistent determining factor across the subdimensions of satisfaction with childbirth, except for physician- and partnerrelated satisfaction. The more expectations were met, the more women were satisfied. Another important factor is the experience of personal control, which buffered even the lowering impact of labour pain for midwife-related satisfaction. Finally, women with high self-efficacy showed more satisfaction with their own performance, as well as the support of midwife and physician. The model is applicable to the satisfaction scores of both Belgian and Dutch women.

\section{Discussion}

In a sample of 311 Dutch and 249 Belgian women, we tested a model including four social psychological determinants of satisfaction with childbirth which have been the subject of other childbirth satisfaction research: the experience of labour pain [19-23], personal control $[15,20,21,23,24]$, self-efficacy $[25,26]$ and the fulfilment of expectations [19-21]. Characteristics of childbirth 


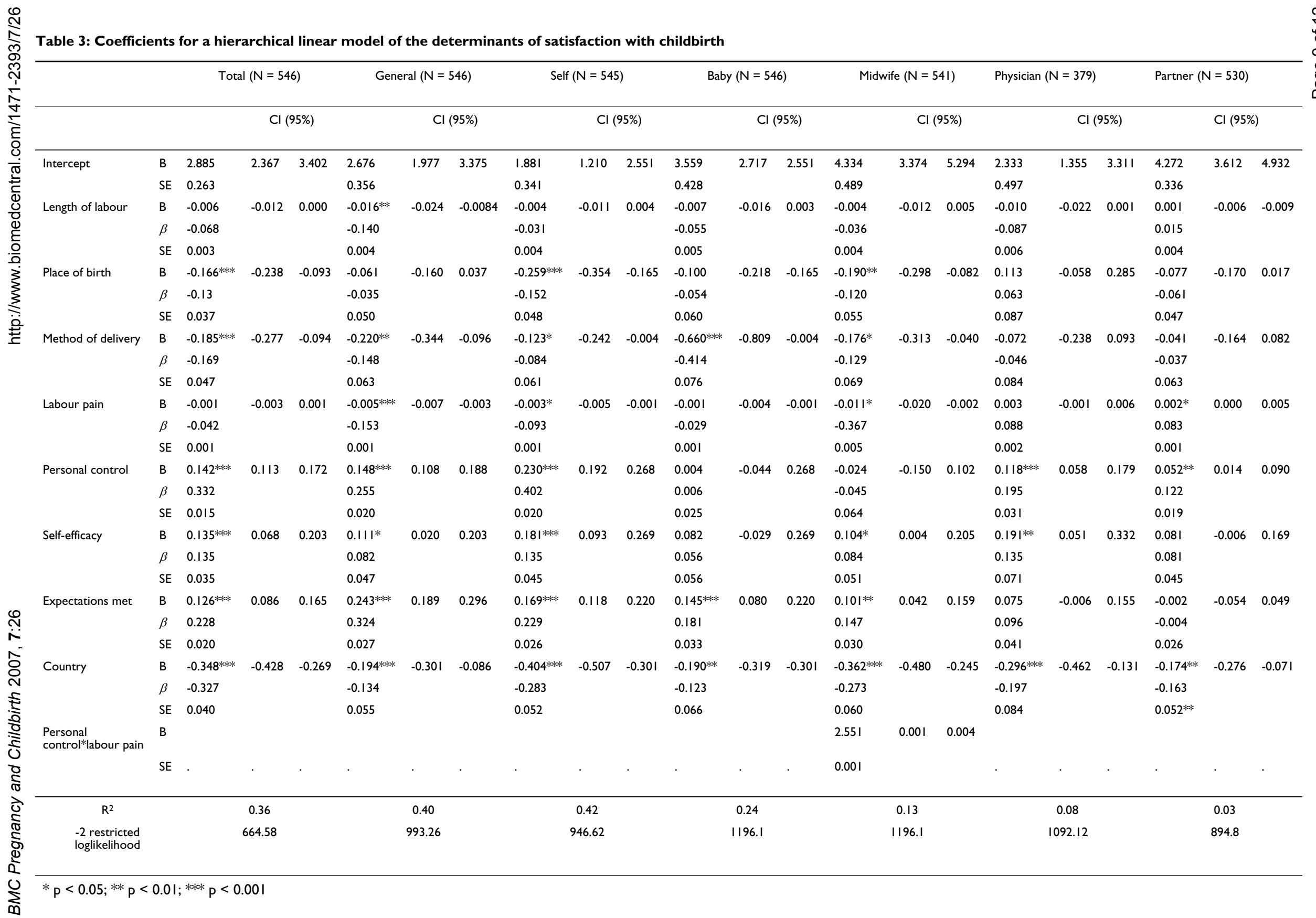


(such as intended place of birth, length of labour, method of delivery) and of the mother (such as age, parity, level of education, marital status and employment) were controlled for.

Before further discussing the findings, we want to briefly list some of the shortcomings and merits of the study. Weaknesses of our research relate to the timing of the measurement of satisfaction with childbirth. Questionnaires were answered within 2 weeks after delivery. This close to the birthing experience, women might have answered less critically than they would have later on [64]. However, the two-week time frame applied to all respondents and therefore does not affect the differences between the groups compared. Second, comparability of the Dutch and Belgian sample can be questioned: Belgian women were on the average more highly educated, younger at first birth and more likely to give birth for the first time in comparison to the Dutch. The higher education of the Belgian sample can be explained by the over sampling of home births, since in Belgium women preferring a home birth are on the average more highly educated [5]. In the Netherlands women are on the average older at first birth in comparison to Belgium and the rest of Europe [65]. Age and education are controlled for in the analysis. Third, women who refused to participate were not systematically registered. This makes generalization of the results less likely.

Despite the limitations, the inclusion of multiple determinants - labour pain, personal control, self-efficacy and the fulfilment of expectations - into one model proved to be fruitful in explaining satisfaction with childbirth. In addition, we used the Mackey Childbirth Satisfaction Rating Scale to take the multidimensionality of childbirth satisfaction into account. Finally, by estimating the models in both the Belgian and the Dutch sample, we tried to assess the applicability of the model for Belgian and Dutch women. Because both countries have strongly differing maternity care systems, we are confident that the present findings have a more general meaning.

Four important findings arise from this investigation. First, the fulfilment of expectations was the most consistent determining factor of satisfaction with childbirth. Women whose expectations for childbirth were met were more satisfied than those whose expectations were not. This conclusion corresponds to the conceptualisation of satisfaction and confirms previous research $[2,19,20]$. Moreover, by comparing Belgian and Dutch women, we learned that the fulfilment of expectations is equally important to the childbirth satisfaction of both groups. However, this does not exclude the possibility that Dutch and Belgian women's expectations may differ. This is rather likely because of the diverging maternity care sys- tems. Expectations are context specific, but the association between their fulfilment and satisfaction is not. In addition, we learned from this study that Belgian women's expectations were more easily fulfilled than Dutch women's expectations. This is not surprising when taking the high referral rate into account. Nearly one third of all planned home deliveries end up in hospital [66]. The ambivalent Dutch maternity care, with its two sciences of obstetrics [11], might explain the unfulfilled Dutch expectations. In ambivalent social structures, contrary courses of action are simultaneously valued for a single actor in a given situation [67]. The conflicting normative expectations imposed on Dutch women may result in a decreased childbirth satisfaction, because it is impossible to conform, without being deviant at the same time.

Second, we found that personal control consistently improved satisfaction and buffered the lowering impact of labour pain. The latter mediating effect is limited to satisfaction with the midwife's support, but nevertheless it supports conclusions of Doering et al. [1] and Pellino and Ward [68] and points to the importance of including personal control and labour pain in one analysis. This interplay between labour pain and control might explain the lack of consensus about the relationship between labour pain and childbirth satisfaction.

Third, women with high self-efficacy showed more satisfaction, especially with the support of the midwife and the physician. This result corresponds with the findings of Crowe and von Baeyer [45] about self-efficacy leading to positive birth experiences.

Personal control and self-efficacy are mediators in the stress process, as predicted by the social stress model [36]. A demanding birth does not result in dissatisfaction if women keep control, hence feel empowered. The job strain model [69] designed to explain the impact of workrelated stress on health outcomes can equally be applied to childbirth satisfaction. The model postulates that strain results from the joint effects of the demands of a work situation, and the control workers facing those demands, exert [69]. The practical implication of the model is that in redesigning maternity care an increase in personal control can be pursued, even without affecting the demanding nature of birth itself. In other words, the empowerment of labouring women, not the management of childbirth by means of painkillers, leads to satisfactory birth experiences.

Finally, the model explains the satisfaction scores of Belgian and Dutch women, implying that the social psychological determinants affect satisfaction independently of the context in which they operate. 


\section{Conclusion}

Our findings focus attention toward personal control, self-efficacy and expectations about childbirth. Antenatal preparation could enhance mother's satisfaction with childbirth by providing techniques for maintaining control, by the enhancement of self-efficacy and by providing information that gives way to realistic expectations about childbirth. This study confirms the multidimensionality of childbirth satisfaction and demonstrates that different factors predict the various dimensions of satisfaction. Further research should incorporate other potential predictors of satisfaction with childbirth, such as social support. Additionally, cross-national comparative research should further assess the dependence of the determinants of childbirth satisfaction on national organisation of maternity care.

\section{Competing interests}

The author(s) declare that they have no competing interests.

\section{Authors' contributions}

WC carried out the literature review, collected the data, interpreted the results and drafted the manuscript; PB participated in the design of the study, performed statistical analyses and revised the manuscript. Both authors read and approved the final manuscript.

\section{References}

I. Doering SG, Entwisle DR, Quinlan D: Modeling the quality of women's birth experience. Journal of Health and Social Behavior 1980, $21:|2-2|$

2. Goodman P, Mackey MC, Tavakoli AS: Factors related to childbirth satisfaction. Journal of Advanced Nursing 2004, 46:2 I 2-219.

3. Brown S, Lumley J: Satisfaction with care in labor and birth: a survey of $\mathbf{7 9 0}$ Australian women. Birth 1994, 2 I(I):4-I3.

4. Coffie D, Wiegers T, Schellevis F: Het gebruik van verloskundige zorg en kraamzorg (The use of maternity care and home care assistence). Tijdschrift voor verloskundigen 2003:3 I 5-320.

5. Gilleir C: Thuis bevallen in Vlaanderen: een kwestie van reflexiviteit (Home birth in Flanders: a matter of reflexivity). Tijdschrift voor Sociologie 2007, 28:25-5I.

6. Wiegers TA, van der Zee J, Keirse MJ: Maternity care in The Netherlands: the changing home birth rate. Birth 1998 25(3): $190-197$.

7. van Teijlingen E: A critical analysis of the medical model as used in the study of pregnancy and childbirth. Sociological Research Online 2005, I0: [http://www.socresonline.org.uk/10/2/tei jlingen.html]

8. Bendelow GA, Williams SJ: Transcending the dualisms Towards a sociology of pain. Sociology of Health \& Illness 1995, I 7:139-165.

9. Mckay S: Models of midwifery care - Denmark, Sweden, and the Netherlands. Journal of Nurse-Midwifery I993, 38: I |4- I 20.

10. Benoit C, Wrede S, Bourgeault I, Sandall J, De Vries R, van Teijlingen ER: Understanding the social organisation of maternity care systems: midwifery as a touchstone. Sociology of Health \& IIIness 2005, 27:722-737.

II. DeVries R: The warp of evidence-based medicine: lessons from Dutch maternity care. International Journal of Health Services 2004, 34:595-623.

12. Scherjon S: A comparison between the organization of obstetrics in Denmark and the Netherlands. BrJ Obstet Gynaecol 1986 93(7):684-689.
13. Gooris FMC, Hingstman L: De rol en positie van vroedvrouwen in België en Nederland (The role and position of midwives in Belgium and the Netherlands). Gezondheid en samenleving 1985 , 6:276-285.

14. Christiaens W, Bracke P: Place of birth and satisfaction with childbirth in Belgium and the Netherlands. Midwifery 2007 in press. [Epub ahead of print]

I5. Bramadat IJ, Driedger M: Satisfaction with childbirth: theories and methods of measurement. Birth 1993, 20(I):22-29.

16. Linder-Pelz S: Toward a theory of patient satisfaction. Social Science \& Medicine 1982, 16:577-582.

17. Williams B: Patient satisfaction - A valid concept. Social Science \& Medicine 1994, 38:509-516.

18. Hodnett ED: Pain and women's satisfaction with the experience of childbirth: a systematic review. Am J Obstet Gynecol 2002, I 86(5 SuppI Nature):SI60-SI72.

19. Green JM: Expectations and experiences of pain in labor: findings from a large prospective study. Birth 1993, 20:65-72.

20. Slade P, Macpherson SA, Hume A, Maresh M: Expectations, experiences and satisfaction with labor. British Journal of Clinical Psychology 1993, 32:469-483.

21. Waldenstrom U, Borg IM, Olsson B, Skold M, Wall S: The childbirth experience: a study of $\mathbf{2 9 5}$ new mothers. Birth 1996, 23:144-153.

22. Brown S, Lumley J: The $\mathbf{1 9 9 3}$ Survey of Recent Mothers: issues in survey design, analysis and influencing policy. Int J Qual Health Care 1997, 9(4):265-275.

23. Lavender T, Walkinshaw SA, Walton I: A prospective study of women's views of factors contributing to a positive birth experience. Midwifery 1999, I 5:40-46

24. Simkin P: Just another day in a womans life: womens longterm perceptions of their Ist birth experience. Birth 199|, I 8:203-210

25. Lowe NK: Maternal confidence for labor - Development of the childbirth self-efficacy inventory. Research in Nursing \& Health 1993, 16:141-149.

26. Larsen KE, O'Hara MW, Brewer KK, Wenzel A: A prospective study of self-efficacy expectancies and labour pain. Journal of Reproductive and Infant Psychology 200I, I 9:203-2I4.

27. Kannan S, Jamison RN, Datta S: Maternal satisfaction and pain control in women electing natural childbirth. Regional Anesthesia and Pain Medicine 200I, 26:468-472.

28. Dickinson JE, Paech MJ, McDonald SJ, Evans SF: Maternal satisfaction with childbirth and intrapartum analgesia in nulliparous labour. Australian \& New Zealand Journal of Obstetrics \& Gynaecology 2003, 43:463-468.

29. Lowe NK: The nature of labor pain. Am J Obstet Gynecol 2002 I 86(5 Suppl Nature):SI6-S24.

30. Humenick SS: Mastery - the key to childbirth satisfaction - A review. Birth and the Family Journal 1981, 8:79-83.

31. Pascoe GC: Patient satisfaction in primary care: a literature review and analysis. Evaluation and Program Planning 1983, 6: $185-210$.

32. Janzen JA, Silvius J, Jacobs S, Slaughter S, Dalziel W, Drummond N What is a health expectation? Developing a pragmatic conceptual model from psychological theory. Health Expectations 2006, 9:37-48.

33. Carr-Hill RA: The measurement of patient satisfaction. Journal of Public Health Medicine 1992, I 4:236-249.

34. Sitzia J, Wood N: Patient satisfaction: a review of issues and concepts. Social Science \& Medicine 1997, 45:|829-|843.

35. Mirowsky J, Ross CE: Social pattern of distress. Annual Review of Sociology 1 986, I 2:23-45.

36. Pearlin LI: The sociological-study of stress. Journal of Health and Social Behavior 1989, 30:24I-256.

37. Cleary PD, McNeil BJ: Patient satisfaction as an indicator of quality care. Inquiry 1988, 25(I):25-36.

38. Staniszewska S, Ahmed L: The concepts of expectation and satisfaction: do they capture the way patients evaluate their care? Journal of Advanced Nursing 1999, 29:364-372.

39. Mahon PY: An analysis of the concept 'patient satisfaction' as it relates to contemporary nursing care. Journal of Advanced Nursing 1996, 24:1241-1248.

40. Booth CL, Meltzoff AN: Expected and actual experience in labour and delivery and their relationship to maternal 
attachment. Journal of Reproductieve and Infant Psychology 1984, 2:79-91.

41. Gibbins J, Thomson AM: Women's expectations and experiences of childbirth. Midwifery 200I, I7:302-3I3.

42. Kabakian-Khasholian T, Campbell O, Shediac-Rizkallah M, Ghorayeb F: Women's experiences of maternity care: satisfaction or passivity? Social Science \& Medicine 2000, 51:103-I I3.

43. Davenport-Sleck B, Boylan CH: Psychological correlates of childbirth pain. Psychosomatic Medicine 1974, 36:215-223.

44. Thoits PA: Stress, coping, and social support processes Where are we - What next. Journal of Health and Social Behavior 1995:53-79.

45. Crowe K, von Baeyer C: Predictors of a positive childbirth experience. Birth 1989, 16(2):59-63.

46. Lowe NK: Explaining the pain of active labor - the importance of maternal confidence. Research in Nursing \& Health 1989, 1 2:237-245.

47. Dilks FM, Beal JA: Role of self-efficacy in birth choice. J Perinat Neonatal Nurs 1997, II (I): I-9.

48. Seeman M: On the meaning of alienation. American Sociological Review 1959, 24:783-79|.

49. Williams K, Umberson D: Medical technology and childbirth: experiences of expectant mothers and fathers. Sex Roles 1999 $4 I: \mid 47-168$

50. Van der Hulst LAM: Dutch midwives: relational care and birth location. Health \& Social Care in the Community 1999, 7:242-247.

5I. Longworth L, Ratcliffe J, Boulton M: Investigating women's preferences for intrapartum care: home versus hospital births. Health and Social Care in the Community 200I, 9:404-4I3.

52. Fleming AS, Ruble DN, Anderson V, Flett GL: Place of childbirth influences feelings of satisfaction and control in Ist-time mothers. Journal of Psychosomatic Obstetrics and Gynecology 1988 8:I-17.

53. Torres A, Reich MR. The shift from home to institutional childbirth - A comparative-study of the United-Kingdom and the Netherlands. International Journal of Health Services 1989, 19:405-4|4.

54. K. K, M. M: Longitudinal study of the intensity of memorized labour pain. Internationl Journal of Nursing Practice 200I, 7:46-53

55. Ip WY: Relationships between partner's support during labour and maternal outcomes. Journal of Clinical nursing 2000 9:265-272.

56. Stockman AF, Altmaier EM: Relation of self-efficacy to reported pain and pain medication usage during labor. Journal of Clinical Psychology in Medical Settings 200I, 8:161-166.

57. Scrimshaw SV, Maher C: Responsiveness of visual analogue and McGill pain scale measures. Journal of Manipulative and Physiological Therapeutics 200I, 24:50I-504.

58. Jenkinson C, Carroll D, Egerton M, Frankland T, Mcquay H, Nagle C: Comparison of the sensitivity to change of long and shortform pain measures. Quality of Life Research 1995, 4:353-357.

59. Wijma K, Wijma B, Zar M: Psychometric aspects of the WDEQ; a new questionnaire for the measurement of fear of childbirth. J Psychosom Obstet Gynecol 1998, 19(2):84-97.

60. Pearlin LI, Schooler C: Structure of coping. Journal of Health and Social Behavior 1978, 19:2-21.

6I. Kempen GIJM: Psychometric properties of GLAS baseline measures: A pilot study (in Dutch) Groningen, Northern Centre for Healthcare Research, University of Groningen; 1992

62. De Vries R, Lemmens T: The social and cultural shaping of medical evidence: case studies from pharmaceutical research and obstetric science. Social Science \& Medicine 2006, 62:2694-2706.

63. Peugh JL, Enders CK: Using the SPSS mixed procedure to fit cross-sectional and longitudinal multilevel models. Educational and Psychological Measurement 2005, 65:8I I-835.

64. van Teijlingen E, Hundley V, Rennie AM, Graham W, Fitzmaurice A Maternity satisfaction studies and their limitations: "What is, must still be best". Birth 2003, 30(2):75-82.

65. Beets G: De timing van het eerste kind: een overzicht (Timing of the first child: an overview). Bevolking en Gezin 2004, 33: II5-142.

66. Reuwer PJHM, Bruinse JW: Preventive support of labour, een uitdaging voor verloskundigen, gynaecologen en beleidsmakers (Preventive support of labour, a challenge to midwives, obstetricians and policymakers) Alphen aan de Rijn, Van Zuiden Communications BV; 2002.
67. Handel W: Normative expectations and the emergence of meaning as solutions to problems - Convergence of structural and interactionist views. American Journal of Sociology 1979 , 84:855-88।.

68. Pellino TA, Ward SE: Perceived control mediates the relationship between pain severity and patient satisfaction. I Pain Symptom Manage 1998, I 5(2): I I0-I I6.

69. Karasek RA: Job demands, job decision latitude, and mental strain - Implications for job redesign. Administrative Science Quarterly 1979, 24:285-308.

\section{Pre-publication history}

The pre-publication history for this paper can be accessed here:

http://www.biomedcentral.com/1471-2393/7/26/prepub
Publish with Bio Med Central and every scientist can read your work free of charge

"BioMed Central will be the most significant development for disseminating the results of biomedical research in our lifetime. "

Sir Paul Nurse, Cancer Research UK

Your research papers will be:

- available free of charge to the entire biomedical community

- peer reviewed and published immediately upon acceptance

- cited in PubMed and archived on PubMed Central

- yours - you keep the copyright

Submit your manuscript here:

http://www.biomedcentral.com/info/publishing_adv.asp
BioMedcentral 